Shelley Hasinoff and David Mandzuk

Case Studies in Educational Foundations: Canadian Perspectives

Don Mills, ON: Oxford University Press, 2015. 216 pp.

From medical faculties to law faculties to education faculties, case studies are becoming increasingly common and popular in professional education programs. A case study can push the limits of thought while at the same time demand a direct application of a theory or concept. Their ability to combine real world events and dilemmas with concepts and ideas is often an effective way to teach students and prepare for a variety of specific challenges they may face. Sometimes case studies may actually be even more compelling and provocative if they have never happened, or are very unlikely to happen, and are abstracted from reality and common experience. Thought experiments are often used in philosophy courses, where there is no expectation that students will necessarily solve a "real world" dilemma - only that they understand the concept better. But professional education demands something different. A case study is not a thought experiment; it is not only empirical rather than ideal, it is oriented towards improved practice more than theoretical understanding. Case studies can be very effective at engaging teacher education students in foundations classes, which is the focus of this book.

The same year Case Studies in Educational Foundations: Canadian Perspectives appeared, I coauthored a book about philosophy of education in Canada, also with Oxford University Press-Questioning the Classroom: Perspectives on Canadian Education. While both books deal with foundations of education in Canada, they are quite different. Questioning the Classroom is focused intensively on philosophical questions about education in Canada, and raises many questions not considered in Hasinoff and Mandzuk's book. Hasinoff and Mandzuk have assembled an original and worthwhile book geared towards undergraduate foundations of education courses in Canada. A small market to be sure, but this allows for greater focus and more intensive examination of the issues. There is little work on philosophy of education case studies in Canada, only John Portelli and William Hare's What to do? Case Studies for Teachers, first published some twenty-five years ago, in 1993. The contributors to this new volume have an exceptionally wide range of experience in terms of ages taught and geographies covered. What emerges is a highly useful book.

The motive behind this book is to address the continued erosion and marginalization of foundations of education courses in faculties of education in Canada, the narrowing of the field as a whole, and the instrumental attitudes towards teacher preparation that would dispense with thought and critique in place of routinization, mechanization, and thoughtless proceduralism. Erosion of the humanities is occurring in general in universities today, and in the larger culture.

The aim of Case Studies in Educational Foundations is to address prevalent and persistent "unwarranted certainties" ( $\mathrm{xx}$ ) in Canadian education: how to contend with uncertainties that are challenging but unavoidable aspects of education, and how to question and disrupt what are construed as incontestable and unalterable 
certainties. This book presents thirty case studies dealing with the myths, bandwagons, and moral panics that plague education in Canada today.

The notion of "unwarranted certainties" - myths, bandwagons and moral panics - is itself quite interesting and thoughtful. They are described as "socially constructed, often unconscious certainties that are generally resistant to discomforting evidence" (xxi). Of the three unwarranted certainties, the most historically oriented is myths, as it deals with the influence of the past, the "enduring and largely unconscious" (xxi) legacies of past beliefs and practices. Bandwagons are conscious and deliberate trends that are often imposed top down, doing damage and distracting energies from other possibilities. Last comes moral panics, those exaggerated fears based on misrepresentations and stereotypes, which often pass as quickly as they arrive. The hope is that in analyzing these three types of unwarranted certainties students will be inured from their effect, reinforced by these various cases.

The cases cover highly specific and technical pedagogical questions ranging from classroom practice to questions about technology and school libraries, to larger social and political questions. Generally they are well written, well thought out, even sometimes surprising and unsettling. Examples include: an exploration of what is a 'normal' child; the use of rewards and incentives in classrooms; secularism; the use of journals in teacher education courses; high stakes testing; standardization; commercialization; and many more - a total of thirty, ten each of the unwarranted certainties. Each case ends with questions divided into the branches of foundations: history, philosophy, sociology, as well as implications for practice. The 'What would you do?' approach demands that students take a stand, and provide reasons for it, even as it emphasizes just how much teaching involves extremely complex and confounding situations that demand fast paced and high stakes — but always imperfect — decision making.

There is much work that needs to be done to promote and protect the kind of thought and inquiry that the humanities advances and celebrates, and this book is an important part of that project. My critique is more of case studies in general, rather than the book itself. The risk is that case studies orient students too much towards practice, and towards 'what is,' rather than what could be, or has been, different. In that sense they are cautious and conservative and sometimes reproductive, since they use what currently exists as their starting point. The belief that the value of an idea is determined by the ease with which it can be put into practice may in fact limit what we ask of the humanities - which is how I think of foundations courses: the humanities in education. Educational thought may be impoverished even as we find more and more uses. Using schools today as the measure and the criterion of relevance may leave out something that educational thinkers have explored and articulated in the past.

That is perhaps another way to say that much great educational theory is already practical, already concerned with 'cases' in the broadest sense. As an example: one of the most famous books in the history of philosophy of education is a 'case study' of a young Emile, the tutor and student both facing a continuing series of 'cases.'

A case implies a solution or remedy. It sets us up to focus on thinking about the 'right' thing to do, and directs us towards a proper course of action. But foundations and the humanities in education are not necessarily about solving problems. 
Their aim is to open horizons about what is, or was, or could be. If students are already intensively practically oriented, then we are in fact confronted with a profound philosophical question about education: should we meet students where they are and provide them with what they demand? Or should we question those demands and present them with something they would otherwise not likely encounter, or something that no longer is? This is a central concern of history of education. Perhaps it is the job of foundations to get students to think beyond schools, beyond institutions, and to strive to ask new and old philosophical questions about education that are not measured by their capacity to solve problems in institutions today.

With these critiques in mind, perhaps this book could be a nice complement to other historical readings and perspectives.

Trevor Norris

Brock University

David F. Labaree

\section{A Perfect Mess: The Unlikely Ascendency of American Higher Education}

Chicago: University of Chicago Press, 2017. 222 pp.

David Labaree's A Perfect Mess: The Unlikely Ascendency of American Higher Education is intended as a political intervention. His purpose is to warn reformers who have their eyes on higher education to back off; if they try to change American higher education, they will ruin it. He argues that American higher education is a series of contradictions held together in delicate balance. In Labaree's view, the inter- and intra-institutional workings of the sector are so complicatedly interwoven that intervening, in any way, may topple the whole structure. This, he maintains, would be a tragedy; as flawed as the system might seem, it has produced the best universities in the world. American higher education, according to this account, seems to be "gold made from straw." The United States produced the best universities in the world even without strong governmental support and lofty shared purposes, but simply with an abundance of people pursuing self-advantage in various forms. Labaree's message is: don't mess with perfection.

Labaree's intervention is explicitly directed towards reformers associated with either conservative politics or entrepreneurial innovation. But it is also aimed at liberal members and friends of higher education. To these latter groups, his message is: do not make too much of a fuss about declining levels of governmental support or inequalities of access or lack of serious purpose on the part of students or institutional leaders. These are problems, but they are necessary problems. They have existed throughout history and are deeply engrained in the system. In Labaree's view, the good outweighs the bad and the bad is inevitable.

The book is an impressive work of synthetic scholarship and an interesting example of how to use (or misuse) a historical narrative to bolster a political program. 